\title{
Mutation Detection in Glycogen Storage Disease Type II by RT-PCR and Automated Sequencing
}

\author{
Monique M. P. Hermans, ${ }^{1}$ Dik van Leenen, Marian A. Kroos, and Arnold J . J . Reuser \\ Department of Clinical Genetics, Erasmus University Rotterdam, P.O. Box 1738, 3000 DR Rotterdam, The Netherlands
}

Received November 5, 1997

\begin{abstract}
A new method is described for detection of mutations in the lysosomal $\alpha$-glucosidase gene (GAA) leading to Glycogen Storage Disease type II (GSDII). A key feature of the method is isolation and reverse transcription of mRNA followed by PCR amplification of lysosomal $\alpha$-glucosidase CDNA with M13-extended primers. Dye labeled primers are used for cycle sequencing and an ABI PRISM 377 DNA sequencing system for analysis. The method is rapid and complementary to the automated sequencing of all the 19, PCR amplified, coding exons of the GAA gene. The advantages and pitfalls of this new method are discussed in the light of the results obtained with an infantile GSDI I patient. A new splice site mutation in the GAA gene of this patient was identified, IVS16 $(+2 T \rightarrow C)$, resulting in the deletion of 16 base pairs of exon 16 . (C) 1997 Academic Press
\end{abstract}

Glycogen Storage Disease type II (GSDII) is caused by deficiency of lysosomal $\alpha$-glucosidase (acid maltase; EC. 3.2.1.3.) due to mutations in the GAA gene $(1,2)$. The clinical phenotype is primarily determined by the nature of these mutations and the allelic combination in which they occur. Skeletal muscle weakness is the common clinical feature and is rapidly progressive when the enzyme deficiency is complete and slowly progressive when residual activity remains. Patients with the most severe infantile form of the disease succumb in the first year of life by cardiorespiratory failure (3); patients with late onset GSDI I suffer mainly from skeletal muscle weakness and respiratory problems $(4,5)$.

Over 40 mutations in the GAA genehave been identified (for an overview see Internet page http://www. eur.nl/FGG/CH1/pompe/). This was mainly achieved by PCR amplification of the exons using primers in flanking introns followed by sequencing. But the total num-

\footnotetext{
${ }^{1}$ To whom correspondence and reprint requests should be addressed. Fax:-31-10-4362536. E-mail: hermans@ikg.fgg.eur.nl.
}

ber of 19 coding exons makes this method quite laborious. In this paper we describe a new approach to mutation detection in GSDII which is based on reverse transcription of mRNA followed by CDNA amplification and sequence analysis on an ABI PRISM 377 DNA sequencing system using dye-labeled primers in the cycle sequencing reaction.

The advantages and pitfalls of this new method are illustrated by the detection of a novel mutation in the splice donor site of exon 16 of the GAA gene of a patient with infantile GSDII from South Africa (Case D; 6). The splice site is lost and a cryptic splice donor site in exon 16 is used instead, resulting in partial deletion of exon 16 sequences and deficiency of Iysosomal $\alpha$ glucosidase mRNA.

\section{MATERIAL AND METHODS}

Cell culture Fibroblasts were cultured in Dulbecco's modification of Eagle's medium (DMEM) supplemented with $10 \%$ fetal calf serum and antibiotics under $10 \% \mathrm{CO}_{2}$ at $37{ }^{\circ} \mathrm{C}$. Confluent cultures were harvested with trypsin/EDTA, cells were washed twice with PBS and pellets were stored at $-20^{\circ} \mathrm{C}$.

DNA and RNA isolation. Genomic DNA was extracted from cultured fibroblasts using routine procedures (7). RNA was extracted using RNAzol ${ }^{\mathrm{TM}}$ reagent according to the manufacturer's directions (Tel-Test, U.S.A.). Northern blot analysis was as described (6).

Mutation analysis. To perform RT-PCR and cycle sequencing, CDNA was made from $1 \mu \mathrm{g}$ RNA using the Superscript ${ }^{\text {TM }}$ Preamplification System and 100 ng random hexamer primers in a total volume of $20 \mu \mathrm{l}$ (Gibco BRL). PCR was performed using an appropriate pair of forward and reverse primers complementary to the GAA CDNA sequence (Table 1 ). The PCR reaction was performed in a final volume of $50 \mu$ l containing 10 pmol of each of the primers, a $2 \mu$ l aliquot of the cDNA, $250 \mu \mathrm{M}$ of each dNTP, $1 \mathrm{mM} \mathrm{MgCl} 2,1$ unit of Taq polymerase (Gibco-BRL) in 1XPCR buffer (Gibco BRL). The PCR was accomplished in 40 cycles $\left(94^{\circ} \mathrm{C}, 30 \mathrm{sec} ; 59^{\circ} \mathrm{C}, 1 \mathrm{~min} ; 72^{\circ} \mathrm{C}, 1.5 \mathrm{~min}\right.$ ) preceded by $2 \mathrm{~min}$ at $94^{\circ} \mathrm{C}$ and followed by $10 \mathrm{~min}$ at $72^{\circ} \mathrm{C}$. The PCR fragments were purified using the QIAquick PCR purification kit (Qiagen) according to the manufacturer's directions. The concentration of the PCR fragments was estimated by agarose gel electrophoresis in combination with a molecular mass marker (Gibco BRL) and brought to $30 \mathrm{ng} / \mu \mathrm{l}$. Cycle sequencing was carried out using the ABI PRISM $^{\mathrm{TM}}$ Dye Primer Cycle Sequencing Ready Reaction Kit (M13$21 \mathrm{M} 13 \mathrm{~K}$ it for forward and M13 Reverse kit for reverse reactions) 
TABLE 1

Primers Used for Amplification of the Lysosomal $\alpha$-Glucosidase CDNA

\begin{tabular}{|c|c|c|c|c|c|}
\hline Fragment & Primer & Location & Position ${ }^{a}$ & Sequence $\left(5^{\prime} \rightarrow 3^{\prime}\right)$ & $\begin{array}{l}\text { Length } \\
\text { (bp) }\end{array}$ \\
\hline \multirow[t]{2}{*}{ A } & M13f-A & exon 2 & -26 & M13f'-AGG AGC TGT CCA GGC CAT CT & 562 \\
\hline & M13r-A & exon 2 & 500 & M13rd-AGG GTC AGG ATG TCC TTG GG & \\
\hline \multirow[t]{2}{*}{ B } & M13f-B & exon 2 & 388 & M13f-CCA CCC AGC TAC CCC AGC TAC & 650 \\
\hline & M13r-B & exon 6 & 1001 & M13r-CCT GTC GAC CTC CAG CTA AG & \\
\hline \multirow[t]{2}{*}{ C } & M13f-C & exon 5 & 891 & M13f-CTA CCT GGC GCT GGA GGA CGG & 588 \\
\hline & M13r-C & exon $9 / 10$ & 1442 & M13r-CAT ACC TTC CCA ATC AGC GG & \\
\hline \multirow[t]{2}{*}{ D } & M13f-D & exon 9 & 1367 & M13f-GGC CCT ACG ACG AGG GTC TG & 740 \\
\hline & M13r-D & exon 15 & 2070 & M13r-CGG CTC GCT GAA GCT GTA CGG & \\
\hline \multirow[t]{2}{*}{$E$} & M13f-E & exon 12 & 1686 & M13f-CCA GTT TCT CTC CAC ACA CTA & 694 \\
\hline & M13r-E & exon $16 / 17$ & 2343 & M13r-CTC TAT TGG CAC CGT CTG CA & \\
\hline \multirow[t]{2}{*}{$\mathrm{F}$} & M13f-F & exon 16 & 2255 & M13f-TCA CCC CAG TGC TCC AGG C & 715 \\
\hline & M13r-F & exon 20 & 2933 & M13r-CTG CTG CCC GCA CAC AGG & \\
\hline
\end{tabular}

a CDNA position of the 5 '-end of the primer, counted from the ATG startcodon.

${ }^{b}$ Expected length of the PCR fragment including the forward and reverse primers.

c M13f, 21 M 13 forward primer sequence; TGT AAA ACG ACG GCC AGT.

d M13r, M13 reverse primer sequence: CAG GAA ACA GCT ATG ACC.

using the protocol described by the manufacturer (Perkin Elmer). The sample mixture was precipitated in $0.83 \mathrm{M} \mathrm{NH}_{4} \mathrm{AC}$ and $66.7 \%$ ethanol. The DNA pellet was dissolved in $4 \mu \mathrm{IBI}$ loading mix (deionized formamide : $25 \mathrm{mM}$ EDTA/50 mg/ml Blue dextran 5:1). Separation of the fragments was accomplished in a $5 \%$ Long Ranger ${ }^{T M}$ gel (FMC Bioproducts) and analyzed with an ABI PRISM 377 DNA sequencing system.

Genomic DNA was PCR amplified using intronic and exonic primers specific for the GAA gene as described (8). Cycle sequencing was as described above, except that the ABI PRISM ${ }^{\mathrm{TM}}$ Dye Terminator Cycle Sequencing Ready Reaction Kit was used (Perkin Elmer).

\section{RESULTS AND DISCUSSION}

To identify the mutations responsible for lysosomal $\alpha$-glucosidase deficiency in patients suffering from GSDII we have in the past PCR-amplified and sequenced all 19 exons of the GAA gene using exon flanking primers. This method has been quite effective but laborious.

In this report we describe a new approach to identify mutations starting from the patient's mRNA and sequencing first the CDNA by RT-PCR before embarking on genomic DNA analysis. One confluent $25 \mathrm{~cm}^{2}$ tissue culture flask with fibroblasts of the patient is sufficient for RNA extraction and reverse transcription into CDNA using random hexamer primers. The lysosomal $\alpha$-glucosidase cDNA is amplified with 6 sets (A-F) of sequence specific primers which are fused to either the$21 \mathrm{M} 13$ forward or the M13 reverse primer sequence to enable automated sequencing on the ABI PRISM 377 DNA sequencing system using the ABI PRISM Dye Primer Cycle Sequencing Kits (Table 1). The primer sets were chosen such to obtain a high fidelity method for PCR amplification and cycle sequencing. The method was tested in a case of infantileGSDII originating from South Africa (Case D; 6).

Cultured fibroblasts from this patient are devoid of residual Iysosomal $\alpha$-glucosidase activity, and no protein is detectable in a pulse-chase labeling experiment (6). Northern blot analysis failed to demonstrate lysosomal $\alpha$-glucosidase mRNA in cells of the patient suggesting the presence of a mutation inhibiting transcription or destabilizing the lysosomal $\alpha$-glucosidase mRNA (Figure 1).

When RT-PCR was performed as described above DNA fragments (A-F) of proper size were obtained with

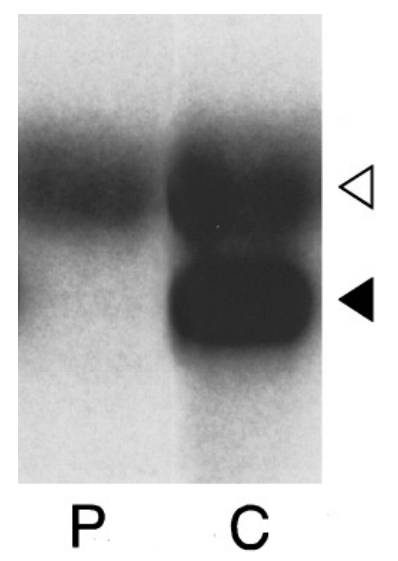

FIG. 1. Northern blot analysis of Iysosomal $\alpha$-glucosidase mRNA of an infantile South African GSDII patient. $20 \mu \mathrm{g}$ RNA was loaded per lane and full-length lysosomal $\alpha$-glucosidase cDNA was used as a probe. The closed arrow head points to lysosomal $\alpha$-glucosidase mRNA, the open arrow head to $28 \mathrm{~S}$ ribosomal RNA which can be used to compare the amount of RNA in each lane. P: patient; C: control individual. 


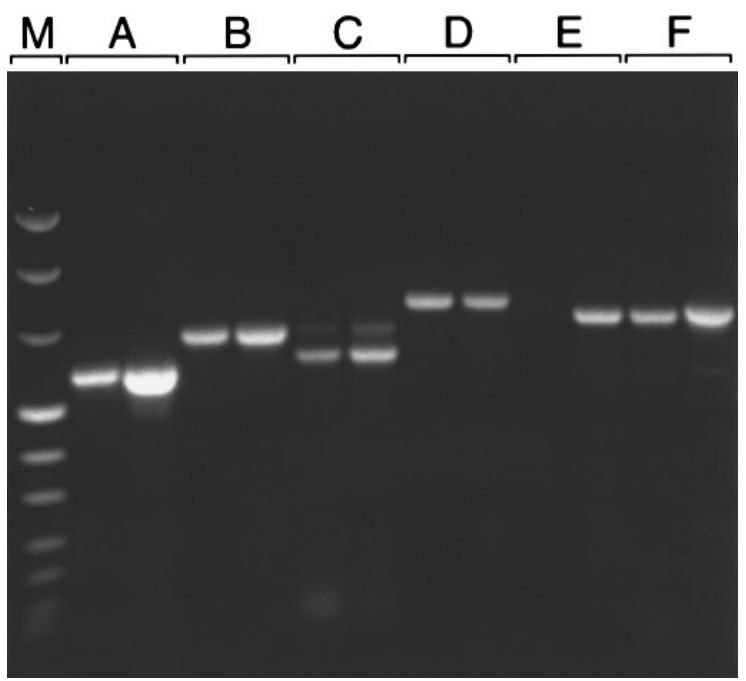

FIG. 2. RT-PCR analysis of Iysosomal $\alpha$-glucosidase mRNA from an infantile South African GSDII patient. mRNA was reverse-transcribed into cDNA and PCR-amplified using lysosomal $\alpha$-glucosidase specific primers. An aliquot of the PCR reaction was applied directly onto a $1.5 \%$ agarose gel. The fragments $(A-F)$ and primers are defined in Table 1. The order of the lanes per primer set is always: Patient, left; Control individual, right. M:Marker VIII (Gibco BRL).

5 of the 6 primer sets illustrating the superior sensitivity of the RT-PCR method over Northern blotting (Figure 2).

Fragment $\mathrm{E}$ of the patient was never amplified, despite the fact that the experiment was repeated several times. This made us aware that a mutation could be located at either the M13f-E or M13r-E primer site. Using M 13f-E and M13r-E in combination with several other primers the amplification problem appeared to be associated with primer M13r-E spanning the boundary of exon 16 and 17. Thus, we amplified a cDNA and genomic fragment spanning this boundary and observed a small, 10-20 base pair, deletion in the cDNA fragment but not in the genomic DNA of the patient (Figure 3). We then sequenced the CDNA and genomic fragments to find the precise molecular defect and discovered that the last 16 base pairs of exon 16 were deleted in the cDNA (del. 2315-2330; Figure 4A). The deletion comprises the last eight 3'-nucleotides of primer $\mathrm{M} 13 \mathrm{r}-\mathrm{E}$; an obvious reason why this primer does not function. The genomic DNA sequence revealed only a single base pair substitution, a $\mathrm{T}$ to $\mathrm{C}$ transition at position +2 in the splice donor site of exon 16 (designated IVS16 $(+2 \mathrm{~T} \rightarrow \mathrm{C})$; Figure 4B). Combining the sequence results we conclude that the IVS16 $(+2 \mathrm{~T} \rightarrow \mathrm{C})$ mutation leads to loss of the regular splice donor site and the use of a cryptic splice donor site in exon 16, resulting in deletion of the last 16 base pairs of exon 16 and leading to a frame shift. Patient D is homozygous for this mutation. This splice site mutation inhib- its apparently transcription or causes instability of the mRNA since no signal is detected on Northern blot.

To further test the RT-PCR automated sequencing approach, the complete open reading frame contained in fragments A-F was sequenced. The sequences of all PCR fragments could be analyzed readily in both directions. No other deleterious mutations were found besides IVS16 $(+2 \mathrm{~T} \rightarrow \mathrm{C}$ ) but several polymorphisms were detected; all homozygous (Table 2).

Of the more than 40 mutations that have been identified in the GAA gene, only few affect splicing. The most frequent GAA mutation, IVS1(-13T $\rightarrow \mathrm{G})$, is conditional for the skipping of exon 2 by aberrant splicing $(9,10)$. Approximately $10-40 \%$ of the lysosomal $\alpha$-glucosidase mRNA is correctly spliced (10-12). This mutation is found world wide and is associated with late onset GSDI I when combined with a null allele (9, 12-14). The two other splice site mutations presently known are IVS6$(-22 T \rightarrow G)$, which creates a strong splice acceptor site in intron 6 and results in the deletion of exon 6 and an inframe insertion of 21 nucleotides of intron 6 (15), and IVS10 $(+1 G \rightarrow C)$ which results in the deletion of exon 10 (9). The IVS16 $(+2 T \rightarrow$ C) mutation identified in our patient results in the activation of a cryptic splice site.

The advantage of our new approach towards mutation detection is evident. Only 6 (cDNA) fragments need to be amplified and sequenced instead of the 18 genomic fragments $(8,16)$. The new method is very sensitive so that the same small number of cells can be used for RNA extraction as for the isolation of genomic DNA.

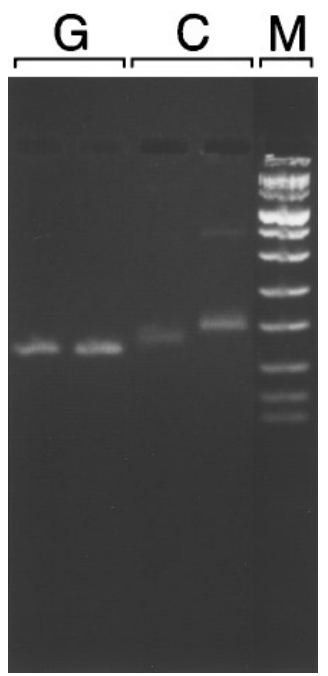

FIG. 3. Analysis of the boundary of exon 16 and 17. A region containing the boundary of exon 16 and 17 was (RT-)PCR amplified from CDNA (C lanes) using primer set $\alpha 16 \mathrm{~m}-\mathrm{f}: 5^{\prime}$-GGCTACTTCCGCTTGGGCACA and EE-r: 5'-CTGCAGGGGGATGATGTACC or genomic DNA (G lanes) using primer set $\alpha \mathrm{CC}$-f: 5'-TCACCCCAGTGCTCCAGGC and N88-r: 5'-TGGTCACACCTGGGA. An aliquot of each reaction was applied directly onto a 3\% Metaphor agarose gel (F MC Bioproducts). The order of the lanes is: Patient, Control. M: Marker VIII. 
However, we have come across pitfalls. The method is obviously not applicable when GAA mRNA from both alleles is fully deficient. In case mRNA is expressed normally from one allele but hardly from the other, the first messenger will be amplified preferentially and no sequence information will be obtained from the second. We did not encounter this problem since the patient analyzed was homozygote. Otherwise is would have been necessary to perform in second instance a complete sequence analysis on the genomic DNA. We advise to use in such instances the method for automated sequencing recently published by Beesley et al. (16). One other pitfall has come to light. One should be aware of mutations preventing the functioning of one of the primers used for (RT-)PCR. This holds for both mRNA and genomic sequencing. When this occurs in a compound heterozygous patient, a non-amplified fragment can be missed easily.

In conclusion, we have demonstrated the use of a new and rapid approach to identify the molecular defects in Iysosomal $\alpha$-glucosidase. The complete open reading frame is amplified in 6 overlapping fragments starting

Normal allele: 2308 - GGCACATGGTACGACCTGCAGACGGTGCCAAT - 2339 Mutant allele:

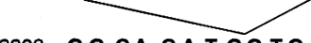

2308- G G CA CA T G G T G C CA A T - 2339

A
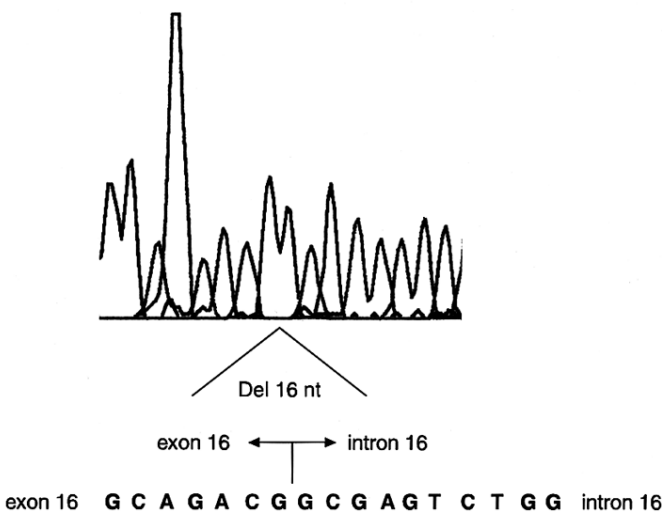

B

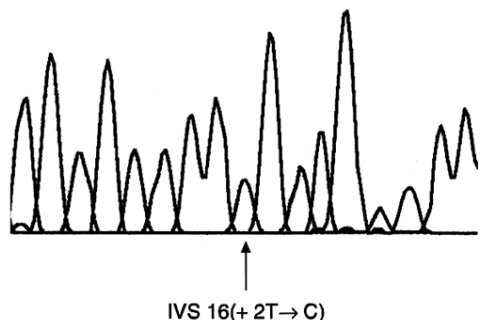

FIG. 4. Identification of IVSI6 $(+2 T \rightarrow C)$. Sequence analysis was performed using the (RT-)PCR automated sequencing approach. A. Partial cDNA sequence of exon 16 and exon 17 of a normal allele and of the mutant allele of the patient showing the deletion of $16 \mathrm{nt}$ (del. 2315-2330). The chromatogram of the mutant allele is shown bel ow the sequence. B. Partial genomic DNA sequence and the chromatogram of exon 16 and intron 16 of the mutant allele of the patient showing the substitution of IVS16 $(+2 \mathrm{~T} \rightarrow \mathrm{C})$.
TABLE 2

Base Pair Substitutions Found in Infantile GSDII Patient

\begin{tabular}{cll}
$\begin{array}{c}\text { Nucleotide } \\
\text { change }\end{array}$ & \multicolumn{1}{c}{ Effect on mRNA/protein } & Location \\
\hline $\begin{array}{c}\text { Mutation } \\
\text { IVS16 }(+2 \mathrm{CT} \rightarrow \mathrm{C})\end{array}$ & Del 16 nt (2315-2330) $\rightarrow$ Frameshift & Exon 16 \\
$\begin{array}{c}\text { olymorphisms } \\
596 \mathrm{G} \rightarrow \mathrm{A}\end{array}$ & $\mathrm{R} 199 \mathrm{H}$ & Exon 3 \\
$668 \mathrm{~A} \rightarrow \mathrm{G}$ & $\mathrm{H} 223 \mathrm{R}$ & Exon 3 \\
$1581 \mathrm{~A} \rightarrow \mathrm{G}$ & $\mathrm{R} 527$ & Exon 11 \\
$2446 \mathrm{G} \rightarrow \mathrm{A}$ & $\mathrm{V} 816 \mathrm{I}$ & Exon 17 \\
$2553 \mathrm{~A} \rightarrow \mathrm{G}$ & $\mathrm{G} 851$ & Exon 18 \\
$2780 \mathrm{C} \rightarrow \mathrm{T}$ & $\mathrm{T} 927 \mathrm{~A}$ & Exon 19 \\
$2862 \mathrm{G} \rightarrow \mathrm{A}$ & - & Exon 20 \\
\hline
\end{tabular}

a Nucleotide numbering is based on the CDNA sequence deposited in the EMBL/GenBank/DDBJ database under Accession No. Y00839 but numbering from the ATG startcodon.

${ }^{\mathrm{b}}$ The exons are defined as in the EMBL/Gen Bank/DDBJ database under Accession Nos. X55079-X55098.

from mRNA rather than genomic DNA, and is sequenced entirely both in forward and reverse directions using the automated sequencing technology. The IVS16 $(+2 T \rightarrow C)$ transition, leading to a 16 base pairs deletion on CDNA is the first mutation that we have found with this approach.

\section{REFERENCES}

1. Hers, H. G. (1963) Biochem. J . 86, 11-16.

2. Reuser, A.J.J., Kroos, M.A., Hermans, M.M.P., Bijvoet, A. G. A., Verbeet, M. P., Van Diggelen, O. P., Kleijer, W. J ., and Van der Ploeg, A. T. (1995) Muscle \& Nerve 3, S61- 69.

3. Pompe, J . C. (1932) Ned. Tijdschr. Geneesk. 76, 304- 311.

4. Engel, A. G. (1986) In Basic and Clinical Myology. (Engel, A. G., and Banker, B. Q., Eds), pp. 1629-1650, McGraw Hill Co.

5. Hirschhorn, R. (1995) In The metabolic and molecular bases of inherited disease (Scriver, C. R., Beaudet, A. L., Sly, W. S., and Valle, D. Eds.) pp. 2443-2464, McGraw Hill Co. Vol II.

6. Van der Ploeg, A. T., Hoefsloot, L. H., Hoogeveen-Westerveld, M., Petersen, E. M., and Reuser, A. J . J A. J . (1989). Am. J . Hum. Genet. 44, 787-793.

7. Sambrook, J ., Fritsch, E. F., and Maniatis, T. (1989) Molecular Cloning: A Laboratory Manual, Cold Spring Harbor Press, Cold Spring Harbor.

8. Kroos, M. A., Young, E. P., J oosse, M., Winchester, B., Reuser, A. J . J ., and MacDermot, K. D. (1997a) J . Inher. Metab. Dis. 20, 556- 558.

9. Huie, M. L., Chen, A. S., Tsujino, S., Shanske, S., DiMauro, S., Engel, S., and Hirschhorn, R. (1994) Hum. Mol. Genet. 3, 22312236.

10. Boerkoel, C. F., Exelbert, R., Nicastri, C., Nichols, R. C., Miller, F. W., Plotz, P. H., and Raben, N. (1995) Am. J . Hum. Genet. 56, 887-897.

11. Raben, N., Nichols, R. C., Martiniuk, F., and Plotz, P. H. (1996) Hum. Mol. Genet. 5, 995- 1000.

12. Kroos, M. A., Van der Kraan, M., Van Diggelen, O.P., Kleijer, W. J ., and Reuser, A. J . J . (1997b) Hum. Mutat. 9, 17- 22. 
13. Kroos, M. A., Van der Kraan, M., Van Diggelen, O.P., Kleijer, W.J., Reuser, A.J.J., Van den Boogaard, M.J., Ausems, M. G. E. M., Ploos van Amstel, H. K., Poenaru, L., Nicolino, N., and Wevers, R. (1995) J. Med. Genet. 32, 836-837.

14. Wokke, J . H. J ., Ausems, M. G. E. M., Van den Boogaard, M. H., I ppel, E. F., Van Diggelen, O., Kroos, M. A., Boer, M., J ennekens,
F. G. I., Reuser, A. J . J ., and Ploos van Amstel, H. K. (1995) Ann. Neurol. 38, 450-454.

15. Adams, E. M., Becker, J . A., Griffith, L., Segal, A., Plotz, P. H., and Raben, N. (1997) Hum. Mutat. 10, 128- 134.

16. Beesley, C. E., Child, A. H., and Yacoub, M. H. (1997) Hum. Mutat. (in press). 